\title{
Health And Safety Of Migrant And Young Workers: Towards A Conceptual Model Of Safety Education For International Students In South Australia
}

\author{
Yahya Thamrin \\ Universitas Hasanuddin \\ Makassar, Indonesia
}

\author{
Dino Pisaniello \\ The University of Adelaide \\ Adelaide, Australia
}

\author{
Cally Guerin \\ The University of Adelaide \\ Adelaide, Australia
}

\begin{abstract}
Despite the possibility of major under-reporting, young workers are over-represented in injury statistics. Among this group are international students, who constitute a significant and rising proportion of young migrant workers. International students may be at greater risk for occupational injury than their domestic peers because of cultural issues, language barriers, financial pressures and the nature of the work available to them. They represent a vulnerable segment of the workforce. Therefore, there is a need to better understand their risk profile and develop educational interventions to reduce risk.
\end{abstract}

Keywords—health and safety; migrant; conceptual model

\section{INTRODUCTION}

Australia has attracted international students who often also become migrant workers [1]. Migrant workers are a growing component of the workforce in Australia. According to McCauley (2005), immigrant workers experience more accidents and injuries and worse severe outcomes than other groups of the whole working population [2].

In Australia young workers were over represented in injury statistics and were twice as likely to experience work-related injury as other workers [3], [4]. This group includes international students.

The existing research in areas related to this topic are mainly focus on either young workers' injury experiences or migrant workers' in term of health and safety issues. There is a scarcity of information regarding health and safety among international students as a subgroup of migrant and young workers in Australia.

This paper provides a review of health and safety issues of international students as migrant and young workers. Firstly, this review develops a picture of migrant workers' health and safety problems, explores young workers' occupational health and safety issues, and then it presents the overlapping vulnerabilities of international students as migrant workers as well as young workers.

This paper is a part of a research project targeted to reduce accident and injuries among international students as young migrant workers by developing a conceptual model of safety education for them.

\section{HEALTH AND SAFETy OF MigRANT WORKERS}

A systematic review about the immigrant population by Ahonen et al. revealed that developed countries had experienced an increased number of migrant workers, which had brought many social and economic problems for the host countries [5]. Hawthorne claimed that in order to prevent the escalation of the number of migrant workers, the Australian Government has started a substantial review of policy related to migration in 1997 by gradually reducing the pathways for unskilled workers[6].

Some studies claimed that language, educational background, and cultural barriers are the most determinant factors for health and safety problems of migrant workers [7] [10]. Migrant workers experienced higher risk of fatal injuries because they do not always understand safety instructions well due to their low level of education and low level of the host country's language. Lack of language skills also presents difficulties for migrant workers when attempting to communicate their needs or problems in the workplace to their employee [11].

Another factor determined the safety in the workplace for migrant workers is duration of residence. Corvalan et al. (1994) stated that the mortality rate of migrant workers with a duration of residence of less than five years increased significantly during 1982-1984 [12]. This finding is supported by Smith \& Mustard who stated that immigrants in their first five years in Canada were at increased risk of work-related severe injuries[9].

The growth number of migrant workers has produced a new mix of ethnicities in worker communities around the world. The potential impact of the growth to the work-related injuries and illness has been presented through some research. In the United States, McCauley reported that immigrant workers experience more accidents and injuries and worse severe outcomes than other groups of the whole working population[2].

A similar pattern found in the US about work related fatalities has been reported in Australia. According to Corvalan et al., the standardized mortality ratio was significantly different between workers from a Non-English 
Speaking Background (NESB) and employees from an English Speaking Background (ESB). This ratio was particularly elevated for people of NESB who had resided in Australia for less than five years which indicated that the highest incidence of work related fatalities was found among migrant workers who are relatively recent arrivals in Australia [12].

\section{HEALTH AND SAFETY OF YOUNG WORKERS}

Much research has been published regarding the vulnerability of young workers. Research by Walters et al. and Rasmussen et al. presents evidence that the incidence of work injuries among young workers is higher than among adults[13][14]. Typically, young workers are concentrated in industries where precarious employment is prevalent, such as agriculture, manufacturing and service [13], [15].

A study by Zierold et al. claimed that the attitude of young workers towards safety in the workplace is a determinant factor for injury[16]. Westaby \& Lowe indicated that coworkers, supervisors and parents also contribute to the risktaking orientation of youths[17]. Moreover, Rasmussen et al. reported that young workers in Denmark found their work was heavy, monotonous, and psychologically demanding and reported it as a factor that increased the rate of injuries[14].

Young workers also face problems associated with policy that affects their health and safety in a workplace. In New Zealand, many young workers are unlisted in the official injury and compensation records because they are not included in the conventional state apparatus designed to protect workers and assist injured or ill adults [15].

A study by Jahan et al. provided the trend of young workers' injuries in South Australia between 1998 and 2007[18]. The study revealed that college and university students are at the highest risk of injury in the workplace. According to Nyland et al., when international students involved in the workplace, the potential hazards and risks exposure due to illegal and unsafe work are even multiplied[19].

Injury and death among young workers is at an alamingly high rate [20]. It was extrapolated that one in 23 young employees experience injury in the workplace in British Columbia and each week five of them are disabled permanently by workplace incidents [20].

Most studies in this review suggest that safety education is important to reduce injury for young workers. However, the current safety education and training for young workers is not effective because the training uses a similar method that is applied to adult workers, which is not suited to youths' developmental levels or interest [16].

The safety training also should focus not only on providing information for identifying reasons for workplace injuries and young workers' rights. Self-advocacy should also be embedded into workplace safety education programs [20], [21].

\section{OVERLAPPING VULNERABILITIES}

Recently, there is a growing number of international students involved in the Australia labor market [19]. However, this sub-group of working population may even more vulnerable compared to their domestic peers [19], [22].

Besides being migrant workers, international students are also young workers and represent a substantial fraction of the young worker population. Young workers suffer from a higher risk of injury in the workplace in comparison with the adult workforce [23].

Migrant workers and young workers are susceptible to accident and injury, and it is reasonable to assume that international students are even more vulnerable than older migrant workers and local young workers. In other words, overseas students are facing the double burden of being young workers as well as migrant workers.

\section{CONCLUSIONS}

International students are very vulnerable subpopulation of the Australian workforce. Hence, it is important to develop interventions to decrease accidents or injuries for this target group not only inside but also outside the workplace. The University as educational provider and the main sponsor of international students to come to Australia may have an important role in addressing the problems, since it has the potential to reach the target group on a large scale outside the workplace. Apart of the university social responsibilities, a conceptual framework of occupational health and safety education should be developed and implemented to reduce the risk.

\section{References}

[1] C. Ziguras and S. Law, "Recruiting international students as skilled migrants: the global 'skills race'as viewed from Australia and Malaysia," Glob. Soc. Educ., vol. 4, no. 1, pp. 59-76, 2006.

[2] L. A. McCauley, "Immigrant workers in the United States," Workplace Health Saf., vol. 53, no. 7, p. 313, 2005.

[3] D. Scott, R. Hockey, R. Barker, D. Sprinks, and R. Pitt, "Half the age twice the risk: Occupational injury in school age children," Inj. Bull. (queensl. Inj. Surveill. Unit) No, vol. 84, 2004.

[4] Y. Thamrin, D. Pisaniello, and S. Stewart, "Time trends and predictive factors for safety perceptions among incoming South Australian university students," J. Safety Res., vol. 41, no. 1, pp. 59-63, 2010.

[5] E. Q. Ahonen, F. G. Benavides, and J. Benach, "Immigrant populations, work and health - a systematic literature review," Scand. J. Work. Environ. Health, pp. 96-104, 2007.

[6] L. Hawthorne, "'Picking Winners': The recent transformation of Australia's skilled migration policy," Int. Migr. Rev., vol. 39, no. 3, pp. 663-696, 2005.

[7] E. Hansen and M. Donohoe, "Health issues of migrant and seasonal farmworkers," J. Health Care Poor Underserved, vol. 14, no. 2, pp. 153-164, 2003.

[8] K. Loh and S. Richardson, "Foreign-born workers: trends in fatal occupational injuries, 1996-2001," Mon. Lab. Rev., vol. 127, p. 42, 2004.

[9] P. M. Smith and C. A. Mustard, "Comparing the risk of work-related injuries between immigrants to Canada and Canadian-born labour market participants," Occup. Environ. Med., vol. 66, no. 6, pp. 361-367, 2009. 
[10] F. Guldenmund, B. Cleal, and K. Mearns, "An exploratory study of migrant workers and safety in three European countries," Saf. Sci., vol. 52, pp. 92-99, 2013

[11] U. Schubert and J. J. Dijkstra, "Working safely with foreign contractors and personnel," Saf. Sci., vol. 47, no. 6, pp. 786-793, 2009.

[12] C. F. Corvalan, T. R. Driscoll, and J. E. Harrison, "Role of migrant factors in work-related fatalities in Australia," Scand. J. Work. Environ. Health, pp. 364-370, 1994.

[13] J. K. Walters, K. A Christensen, M. K Green, L. E Karam, and L. D Kincl, "Occupational injuries to oregon workers 24 years and younger: An analysis of workers' compensation claims, 2000-2007," Am. J. Ind. Med., vol. 53, no. 10, pp. 984-994, 2010.

[14] K. Rasmussen, C. D. Hansen, K. J. Nielsen, and J. H. Andersen, "Incidence of work injuries amongst Danish adolescents and their association with work environment factors," Am. J. Ind. Med., vol. 54, no. 2, pp. 143-152, 2011.

[15] D. Anderson, Z. Hannif, and F. Lamm, "The good, the bad and the ugly: The health and safety of young workers," Young People Work, pp. 87104, 2011.

[16] K. M. Zierold, E. C. Welsh, and T. J. McGeeney, "Attitudes of teenagers towards workplace safety training," J. Community Health, vol. 37, no. 6, pp. 1289-1295, 2012.
[17] J. D. Westaby and J. K. Lowe, "Risk-taking orientation and injury among youth workers: examining the social influence of supervisors, coworkers, and parents.," J. Appl. Psychol., vol. 90, no. 5, p. 1027, 2005.

[18] N. Jahan, D. Pisaniello, S. Stewart, A. Braunack-Mayer, and H. Winefield, "Young worker injury experience in South Australia 1998$2007, " 2010$.

[19] C. Nyland, H. Forbes- Mewett, S. Marginson, G. Ramia, E. Sawir, and S. Smith, "International student- workers in Australia: a new vulnerable workforce," J. Educ. Work, vol. 22, no. 1, pp. 1-14, 2009.

[20] P. Chin, C. DeLuca, C. Poth, I. Chadwick, N. Hutchinson, and H. Munby, "Enabling youth to advocate for workplace safety," Saf. Sci., vol. 48, no. 5, pp. 570-579, 2010.

[21] D. L. Pisaniello, S. K. Stewart, N. Jahan, S. L. Pisaniello, H. Winefield, and A. Braunack-Mayer, "The role of high schools in introductory occupational safety education-Teacher perspectives on effectiveness," Saf. Sci., vol. 55, pp. 53-61, 2013.

[22] D. Anderson, R. Lamare, and Z. Hannif, "The working experiences of student migrants in Australia and New Zealand," Young People Work, pp. 51-66, 2011.

[23] L. Delp, C. W. Runyan, M. Brown, J. M. Bowling, and S. A. Jahan, "Role of work permits in teen workers' experiences," Am. J. Ind. Med., vol. 41, no. 6, pp. 477-482, 2002. 